\title{
IMPORTANCE OF LARVAL CHARACTERS IN CLASSIFICATION
}

\begin{abstract}
A MEETING of Section D (Zoology) of the British A Association was held at Bristol on September 5, with Prof. F. W. R. Brambell in the chair, to consider the importance of larval characters in classification. Dr. F. I. van Emden, who opened the discussion, said that in wingless insects such as the silverfish adult and larva are much alike. In winged insects this is not so, and it is clear that adult and larva must have evolved along quite different lines. It follows that neither adult nor larval characters have over-riding importance for taxonomy : theoret. ically they are of equal importance. Where a resting pupal stage intervenes, many characters are quite unrelated in adult and larva. Where such a stage is absent, larva and adult have often evolved in such different environments that their classification has to be based on entirely different criteria. In practice, either stage may chance to exhibit better taxonomic characters.
\end{abstract}

In most insect groups our knowledge of the larvæ is still exiguous, but a fair number of cases are already known in which the larvæ are easier to distinguish than the adults, for example, among sphingid moths, mosquitoes, Culicoides midges, meloid beetles; and further examples doubtless await discovery. As a rule, however, the adults show a greater degree of differentiation than the larvæ, and consequently their characters are likely to remain more important for species determination. Larval characters, on the other hand, are likely to retain greater importance for classification than for identification. Thus the major divisions of winged insects are named with reference to larval development (Exoptergota, Holometabola, etc.). Larval characters are used extensively in the classification of Diptera, Hymenoptera, Coleoptera and Aphioidea, and they are almost as important as those of the adult for subdividing Odonata and Neuroptera. Examples of changes that have been made mainly, or entirely, with reference to larval characters are : inclusion of the order Strepsiptera in the Coleoptera; removal of the Aphaniptera (fleas) from the Aptergota to a position among winged orders near the Diptera, a step first advocated by Lamarck in 1801. Since classification attempts, at least to some extent, to summarize phylogeny, it follows that larval characters have a similar part to play in phylogenetic studies. Thus acceptance of Chapman's order Zeugloptera implies agreement with the assumption that this group must have separated from the Lepidoptera sooner than did the Trichoptera. Revision of the systematic position of the Archostemata implies a revision of our ideas concerning the evolution of the coleopterous larva. At a lower level, larval characters afford clear evidence regarding the evolution of stridulating organs, armature of the teeth ventrite and other structures.

Finally, larval identification is important not only for taxonomy per se but also for all those branches of biology which taxonomy subserves. For example, the results of quantitative ecological research would be incomplete if larval forms had to be neglected because they could not be identified.

Dr. Isabella Gordon then discussed the systematic position of the Euphausiacea, a small but economically important group of Crustacea Malacostraca once placed with the Mysidacea in the old order 'Schizo- poda'. The best-known member of the single family Euphausiidae is undoubtedly Euphausia superba, the krill or whalefeed. Larval development and adult structure indicate close affinity with the lower Decapoda, especially the Penaeidea, and for the past fifty years Euphausiacea has been considered an independent order of the division Eucarida coordinate with Decapoda. Some twenty years ago the late Dr. Stanley Kemp, then director of the Discovery Investigations, was convinced that Euphausiacea are true Decapoda related to the Sergestidae. Unfortunately his views, though fully endorsed by Calman, were never published, and Gurney (1942) was the first definitely to place Euphausiacea in the Decapoda. His suggested classification is little, if any, improvement on the old one; but his comparison of Euphausid development with that of the Penaeidea is excellent.

Most Eucarida incubate their eggs, which are attached to the abdominal pleopods; but neither Euphausiacea nor Penaeidea do this-their eggs are either shed freely or adhere for a brief period to the posterior thoracic appendages. Moreover, Euphausiacea and Penaeidea are the only Malacostraca with free nauplius larvæ. Penaeidea would appear to be more primitive than Euphausiacea; for example, there is no compression of the thoracic somites such as occurs in all other Eucarida, and the Penaeidae have elongated pear-shaped nauplii. In Euphausiacea there is extreme compression of the thorax and the appearance of the second and subsequent thoracic appendages is long delayed, except in Euphausia superba, which acquires precociously the swimming and feeding habits of the adult. Euphausid development, though gradual as in many Penaeidae, is remarkably close to that of the Sergestidae, where there is abrupt metamorphosis at the end of each phase. In Sergestidae also, there is the same tendency to reduction or loss of the last two pairs of thoracic appendages (post-larva, Lucifer) and, in some species at least, to enlargement and modification of one pair of maxillipeds. Then there is general similarity of such adult structures as the male copulatory petasma and spermatophores, the female sperm receptacle (thelycum) and the photophores. The resemblances far outweigh the differences, chief of which is that in Euphausids the gills, which are specialized podobranchs, are exposed, not concealed by the carapace-but Lucifer has no gills at any stage.

Calman, in a letter dated May 27, 1948, suggested. making the Euphausiidea co-ordinate with Penaeidea, Caridea, etc.; Gurney was in favour of uniting the two groups with free nauplius-protozoea development in one suborder as against the rest of the Decapoda (letter dated February 12, 1949). At present the writer is undecided as to the best course to adopt. The classification of the Decapoda is a very difficult problem, and none of the schemes hitherto proposed is entirely satisfactory. (See also p. 934 of this issue of Nature.)

A review of recent work on larval characters in helminths by Dr. Sheila M. Willmott followed. Many helminths are highly pathogenic parasites of man and animals and, in the case of some nematodes, also of plants. All have complex life-histories including several larval stages. In the three main groups of 
helminths-the nematodes, trematodes and cestodesthe larvæ may show a combination of adult and larval characters. For example, in cestode larvæ the head is identical with that of the adult, but the form of the cyst is a purely larval character; in the nematodes, the gut of the larva may take the form that it shows in the adult. In the digenetic trematodes, the body of the cercaria shows such adult characters as the arrangement of the head and collar spines in the echinostomes, the absence of an cesophagus in the schistosomes and the position of the ventral sucker in the amphistomes; the tail is purely larval, although its form is frequently characteristic of the group to which the adult belongs. The character now most used in the classification of the cercariæ is the basic formula of the excretory system. This frequently resembles the arrangement found in the adult, and the fundamental flame-cell pattern forms a basis for a 'natural' classification.

Hydatid disease, which is widespread throughout the world and is more common in Great Britain than is generally realized, is caused by a larval cestode. Whether one species is responsible for the two types of hydatid disease or whether two species are involved has long been a matter of controversy. Careful investigation of the types of larvæ and the life-cycle have now led to the conclusion that two species of Echinococcus are involved.

Recently much work has been done on larval nematodes, particularly the Spiruroidea, with the result that a scheme of classification proposed twenty years ago and based on the morphology of the head has been confirmed. As many nematodes are freeliving, it is concluded that the parasitic mode of life has been more recently acquired in this group than in the trematodes and cestodes. The degrees of adaptation of nematode larve to the intermediate hosts are probably better indications of phylogenetic relationships than are the relations of the adult to the definitive hosts. Four main types of larvæ are recognized: (1) the most primitive, that is, freeliving larvæ; (2) larvæ developing to the third stage before hatching ; (3) larvæ which develop in a verte. brate intermediate host but which act as ectoparasites rather than as endoparasites; and (4) the most specialized, that is, those which develop in a vertebrate intermediary with a strongly marked degree of 'séclusion' within it, or which have second. arily lost the intermediate host.

The last paper was entitled "The Classification of Nematodes parasitizing Horses, using Larval Characters". Mr. D. Poynter said that to-day the horse commonly harbours large numbers of various species of nematodes, and these are often the cause of retardation in growth, illness and sometimes death. The effects of parasitism have undoubtedly been aggravated by domestication. The typical horse nematode lives as an adult in the intestines of its host and lays eggs which are passed out, with the fæces, on to the pasture. The eggs hatch and give rise to third-stage infective larvæ which live on the herbage and are ingested by the host. Equine nematode parasites all belong to the superfamily Strongyloidea; but the eggs of the various genera and species are indistinguishable from each other. Since the adults are inaccessible within the host, it is essential to obtain the free-living larval stages, and this is done by means of a special culture technique. After seven days at $28^{\circ} \mathrm{C}$. in a frecs-charcoal culture, development has proceeded as far as the third-stage larvæ, which have definite diagnostic characters. These larvæ have been described for some of the genera and species, and a key published in 1948 facilitates the determination of the larvæ obtained from equine fæces. Unfortunately, this key is not illustrated. But a plate has now been prepared showing the various larvæ drawn to the same scale. It is possible, therefore, by identifying the larvæ in a given culture, to obtain knowledge of the types of nematodes in the host. A survey has been undertaken using many horses, and information has been obtained as to the incidence of the different nematodes in hosts of different ages.

This culture procedure has also an important practical application. Parasites of the family Strongylidae are all affected to some extent by phenothiazine, a common anthelmintic which has no effect on Trichostrongylus axei. For this parasite, copper sulphate and nicotine must be used. Any rational treatment, therefore, must include a prior determination of the larvæ. A careful comparison of larval cultures obtained before and after dosing will indicate the effectiveness of a new anthelmintic against the different nematode species. For example, when testing the efficiency of piperazine adipate, it was noted that every adult horse dosed showed an immediate and sharp rise in the number of eggs of Strongylus edentatus being passed. Subsequent critical tests proved the compound to be only $0-6$ per cent effective against this species.

The general discussion which followed not unnaturally centred around the insects. Prof. G. C. Varley emphasized the practical importance to the ecologist of correlating observations on the behaviour of the adults with their life-histories, giving examples from his work on parasitic Hymenoptera. Mr. P. F. Mattingly referred to recent immunological work on mosquito taxonomy, the discovery in mosquitoes of some of the evolutionary anomalies discussed by de Beer in his book "Embryos and Ancestors", and Wigglesworth's recent brilliant exposition of the concept of insect metamorphosis as a special case of the more general phenomenon of polymorphism. He also stressed the need for comparative genetical studies on the inheritance of adult and larval characters.

IsABELIA GoRdoN

\section{INSTITUTE OF PHYSICS REPORT FOR 1954}

$T$ HE thirty-fifth annual report of the Board of the Institute of Physics*, covering the work of the Institute during 1954, was presented to the annual general meeting of the Institute, held at the Institute's house in London on May 17. The report records that the membership in the several grades of the Institute continues to mount steadily, and the total membership has increased by 154 to 4,749 . The newly established examination for entry to the graduateship grade of membership of the Institute was held during June 21-25 at centres in London, Birmingham and Paisley, and nineteen of the fifty: four candidates were successful. The numbers of candidates for the final examinations for National Certificates in Applied Physics were 206 for the Ordinary level and 75 for the Higher Certificate,

- Thirty-fifth Annual Report of the Board of the Institute of Physics, 1954. Pp. 25. (London: Institute of Physics, 1955.) 